\title{
An association between the endothelial nitric oxide synthase gene G894T polymorphism and premature coronary artery disease: a meta-analysis
}

\author{
Boqian Zhu ${ }^{1, *}{ }^{,}$Xinmin $\mathrm{Si}^{2, *}$, Yaoyao Gong ${ }^{2, *}$, Gaoliang Yan ${ }^{1}$, Dong Wang ${ }^{1}$, Yong Qiao ${ }^{1}$, \\ Bo Liu ${ }^{1}$, Jiantong Hou ${ }^{1}$ and Chengchun Tang ${ }^{1, *}$ \\ ${ }^{1}$ Department of Cardiology, Zhongda Hospital, Southeast University, Nanjing, China \\ ${ }^{2}$ Department of Gastroenterology, The First Affiliated Hospital of Nanjing Medical University, Nanjing, China \\ *These authors contributed equally to this work \\ Correspondence to: Chengchun Tang, email: tangchengchun@medmail.com.cn \\ Keywords: premature coronary artery disease, G894T, Glu298Asp, polymorphism, endothelial nitric oxide synthase
}

Received: March 02, 2017 Accepted: July 29, $2017 \quad$ Published: August 23, 2017

Copyright: Zhu et al. This is an open-access article distributed under the terms of the Creative Commons Attribution License 3.0 (CC BY 3.0), which permits unrestricted use, distribution, and reproduction in any medium, provided the original author and source are credited.

\section{ABSTRACT}

Previous epidemiological studies have suggested that genetic factors are more likely to influence the development of premature coronary artery disease (CAD) than disease in older patients. Several studies have evaluated the association between the G894T polymorphism located in an exon of endothelial nitric oxide synthase (eNOS) and the risk of premature CAD. However, the findings were inconsistent. Thus, we performed a meta-analysis to clarify the association; we conducted both overall and subgroup analyses. Odds ratios and $95 \%$ confidence interval were calculated to evaluate the association between the G894T polymorphism and the risk of premature CAD. Overall analysis revealed a significant association. Subgroup analysis in terms of ethnicity revealed a significant association, in all models evaluated, between the G894T polymorphism and susceptibility to premature CAD in mixed population. In contrast, no such association was evident in Caucasians and Asians. On further subgroup analysis based on the premature CAD subtypes, we found that the G894T polymorphism was correlated with premature myocardial infarction (MI) but not with premature CAD without MI. In conclusion, we confirmed that the eNOS G894T polymorphism is a risk factor for premature CAD, particularly in those suffering premature MI.

\section{INTRODUCTION}

Coronary artery disease (CAD) is one of the leading causes of morbidity and mortality worldwide [1]. Genetic factors, diabetes mellitus, hypertension, hyperlipidemia, obesity, and smoking are major risk factors for CAD [2]. Premature $\mathrm{CAD}$, defined as $\mathrm{CAD}$ developing in males aged $<55$ years and females aged $<65$ years, has become more prevalent in recent years, particularly in developing countries [3]. Genetic factors seem to play a prominent role in the development of premature CAD [4]. Earlier epidemiological data suggested that such genetic factors were more likely to affect younger than older subjects [3]. Premature CAD is generally associated with a low atherosclerotic burden in the coronary arteries and a family history of CAD [5-6].

Previous studies found that endothelial dysfunction plays a critical role in atherosclerosis progression [7-8]. Endothelial cells produce nitric oxide (NO) synthesized from L-arginine by endothelial nitric oxide synthase (eNOS). NO promotes vasodilation and inhibits platelet aggregation, leukocyte adhesion to the vascular endothelium, oxidation of low-density lipoproteins, and proliferation of vascular smooth muscle cells [9]. Thus, eNOS exerts an atheroprotective role [10].

NO production levels are influenced by several polymorphisms in the eNOS gene located on chromosome 7q35-36; the gene contains 26 exons with a total length 
of $21 \mathrm{~kb}$, and the encoded protein is responsible for intracellular NO production [11]. Over the past two decades, several eNOS gene polymorphisms have been associated with CAD or myocardial infarction (MI) [12-14].

A variant of the eNOS gene within exon 7, a $\mathrm{G} \rightarrow \mathrm{T}$ transversion at nucleotide position 894 of the cDNA, changes Glu298 (GAG) to Asp (GAT) [15]. Several studies have shown that the G894T (Glu298Asp) polymorphism is associated with premature CAD, but the data are conflicting. Therefore, we conducted a metaanalysis to better understand the correlation between the G894T (Glu298Asp) polymorphism and premature CAD development.

\section{RESULTS}

\section{Characteristics of the included studies}

A total of 345 relevant studies were identified by the initial search. After full-text review, 335 studies that did not meet the inclusion criteria, contained inadequate data, or were duplicates were excluded. Finally, 10 studies were included [4, 16-24]. The selection process is illustrated in Figure 1. The studies included 1,894 premature CAD patients and 2,096 controls. Of the included studies, five were conducted on Caucasians, two on Asian populations and three on mixed populations. Six studies evaluated premature CAD (premature coronary stenosis) and four premature MI. All genotype distributions were consistent with HWE $(P>0.05)$. The characteristics of the included studies are summarized in Table 1.

\section{The overall meta-analysis}

Figure 2 presents a summary of the ORs, with corresponding $95 \%$ CIs, for the association between the G894T polymorphism and the risk of premature CAD as revealed using the allelic, dominant, and recessive models. We employed a random-effects method when running all models to determine the $P$ values for heterogeneity. Overall, we found a significant association between the G894T polymorphism and premature $\mathrm{CAD}$ in the allelic $(\mathrm{OR}=1.31$, $95 \%$ CI $1.01-1.71 ; P=0.045)$ and recessive $(\mathrm{OR}=1.67$, $95 \%$ CI 1.08-2.58; $P=0.022)$ models, but not in the dominant model $(\mathrm{OR}=1.28,95 \%$ CI $0.97-1.69 ; P=0.09)$.

\section{Subgroup analysis}

Given that significant heterogeneity was apparent in the overall analysis, we performed subgroup analyses by ethnicity and disease type. Any possible contribution of ethnicity to variations in the overall estimates was evaluated by analyzing the data according to race: Caucasian (five studies recruited 1,238 cases and 1,497 controls), Asian (two studies recruited 245 cases and 196 controls) and mixed population (three studies recruited 411 cases and

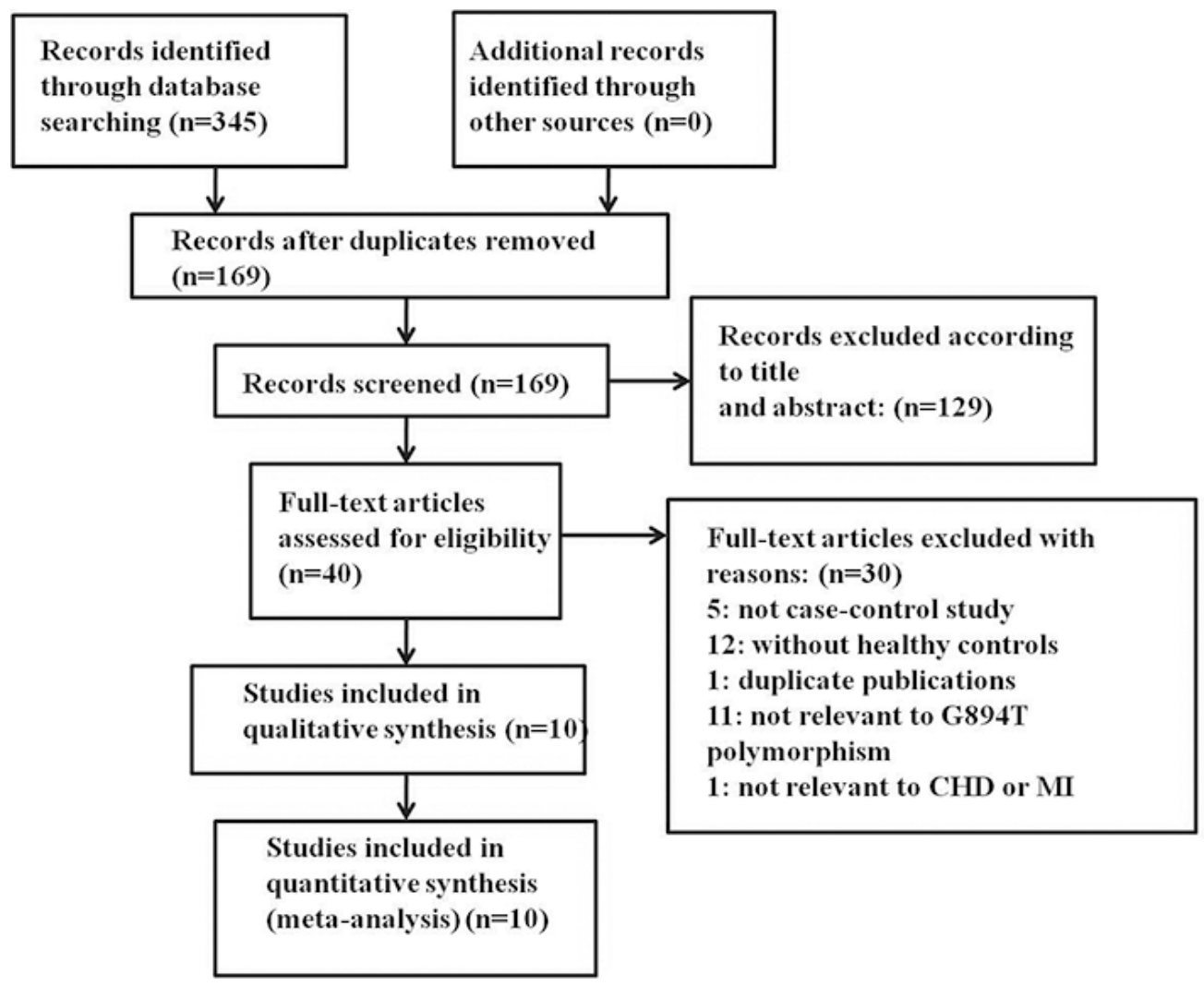

Figure 1: Flow chart of the literature search. 
Table 1: Characteristics of included studies in this meta-analysis

\begin{tabular}{|c|c|c|c|c|c|c|c|c|c|c|c|c|c|c|}
\hline \multirow{3}{*}{ G894T } & \multirow[t]{3}{*}{ Year } & \multirow[t]{3}{*}{ Ethnicity } & \multirow[t]{3}{*}{ Case } & \multicolumn{6}{|c|}{ Genotype } & \multirow[t]{3}{*}{ Sample size } & \multirow[t]{3}{*}{$\%$ of male (case/control) } & \multirow[t]{3}{*}{$\begin{array}{c}\text { Age mean } \\
\text { (case/control) }\end{array}$} & \multirow[t]{3}{*}{ P for HWE } & \multirow[t]{3}{*}{ NOS } \\
\hline & & & & \multicolumn{3}{|c|}{ Case } & \multicolumn{3}{|c|}{ Control } & & & & & \\
\hline & & & & GG & GT & TT & GG & GT & TT & & & & & \\
\hline Granath & 2001 & Caucasian & premature $\mathrm{CAD}$ & 260 & 248 & 63 & 270 & 287 & 66 & $573 / 624$ & $0.87 / 0.51$ & $43.9 / 40.9$ & 0.424 & 7 \\
\hline Wu & 2003 & Asian & premature $\mathrm{CAD}$ & 91 & 23 & 0 & 53 & 10 & 2 & $114 / 65$ & $0.95 / 0.83$ & $46.9 / 49.2$ & 0.108 & 7 \\
\hline Cam & 2005 & Caucasian & premature $\mathrm{CAD}$ & 44 & 37 & 34 & 57 & 24 & 2 & $115 / 83$ & $0.77 / 0.78$ & $48.2 / 44.6$ & 0.777 & 6 \\
\hline Antoniades & 2005 & Caucasian & premature MI & 97 & 99 & 32 & 255 & 217 & 47 & $228 / 519$ & $0.93 / 0.90$ & $46.9 / 47.2$ & 0.932 & 8 \\
\hline Vasilakou & 2008 & Caucasian & premature $\mathrm{CAD}$ & 109 & 85 & 15 & 76 & 74 & 11 & $209 / 161$ & $0.83 / 0.51$ & $52.3 / 65.6$ & 0.212 & 6 \\
\hline Isordia-Salas & 2010 & Mixed & premature MI & 104 & 62 & 14 & 134 & 42 & 4 & $180 / 180$ & $0.75 / 0.72$ & $39.3 / 39.7$ & 0.742 & 8 \\
\hline Jiang & 2012 & Asian & premature $\mathrm{CAD}$ & 117 & 12 & 2 & 111 & 19 & 1 & $131 / 131$ & $0.60 / 0.60$ & $54.4 / 53.8$ & 0.851 & 6 \\
\hline Abdel-Aziz & 2013 & Mixed & premature CAD & 48 & 46 & 22 & 68 & 39 & 12 & $116 / 119$ & $0.78 / 0.53$ & $42.4 / 41.9$ & 0.085 & 6 \\
\hline Zigra & 2013 & Caucasian & premature MI & 50 & 46 & 11 & 50 & 42 & 11 & $107 / 103$ & NA & $32.5 / 31.8$ & 0.626 & 8 \\
\hline Sampaio & 2007 & Mixed & premature MI & 56 & 46 & 13 & 52 & 45 & 7 & $121 / 111$ & $0.72 / 0.67$ & $34.4 / 33.3$ & 0.509 & 7 \\
\hline
\end{tabular}

CAD: Coronary artery disease. MI: myocardial infarction. HWE: Hardy-Weinberg equilibrium. NA: not available. NOS: Newcastle-Ottawa scale.

A

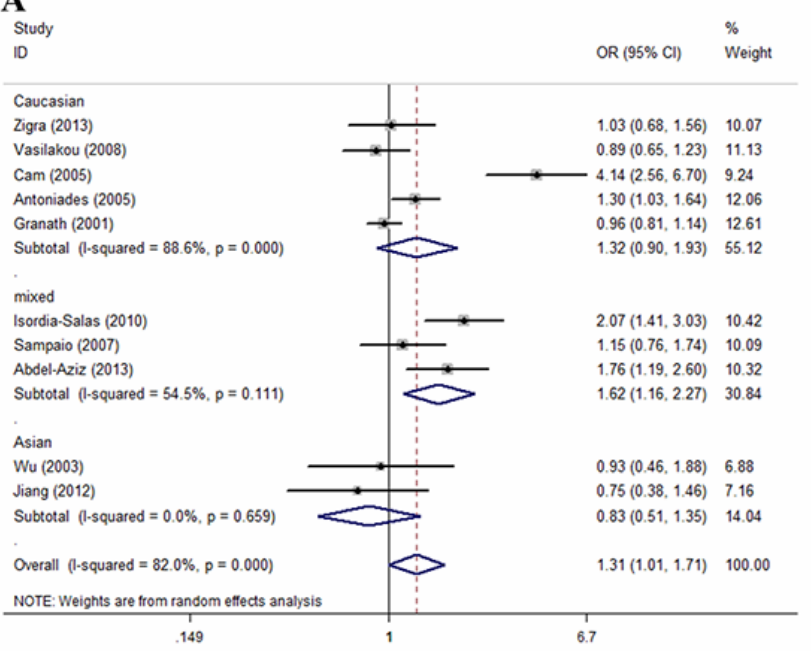

B

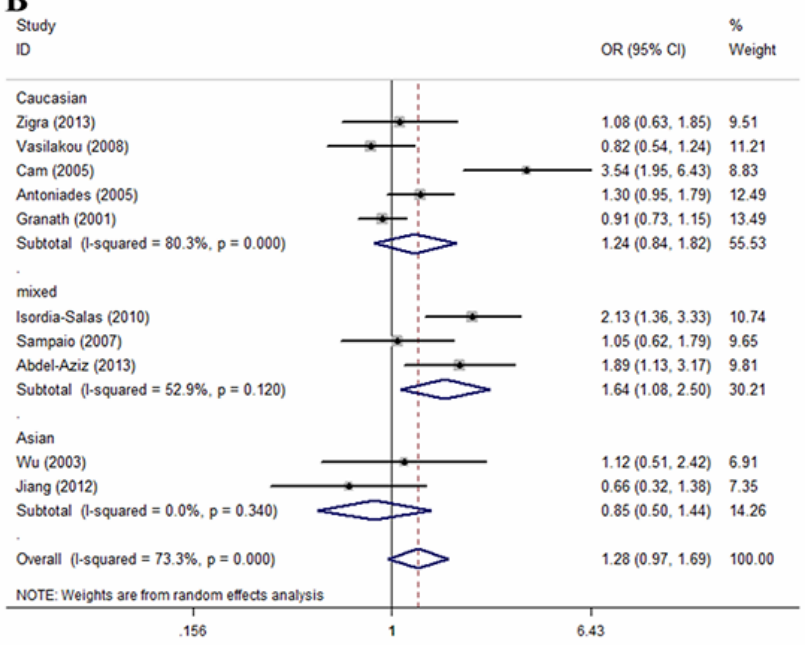

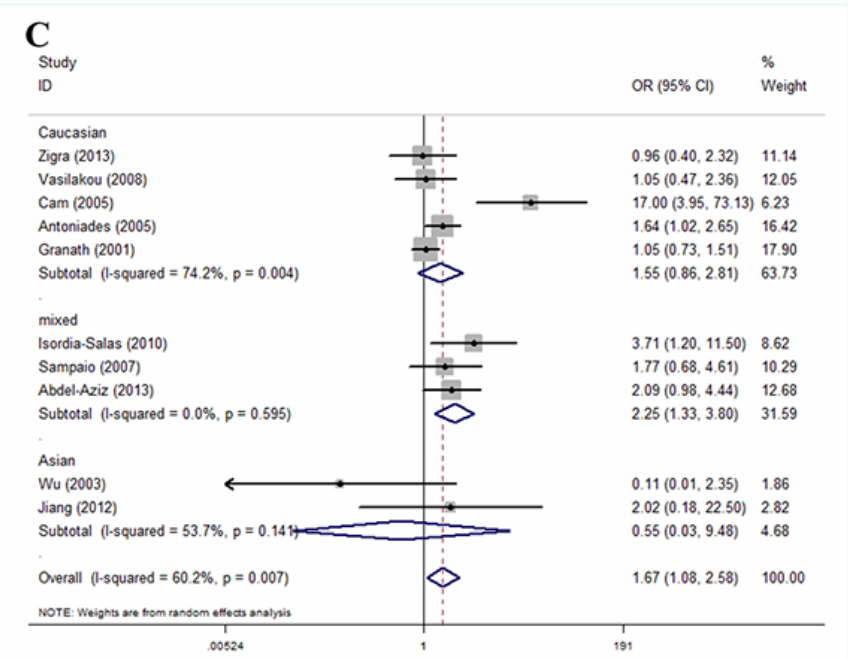

Figure 2: Forest plots of the ORs with 95\% CIs, using different genetic models, for the association between the G894T polymorphism and the risk of CAD in patients stratified by ethnicity. (A) Allelic, (B) dominant, and (C) recessive models. 
403 controls). We found a significant association between the G894T polymorphism and the risk of premature CAD among mixed population when the allelic, dominant, and recessive models were employed. The ORs for the mixed population subgroup were 1.62 (95\% CI 1.16-2.27; $P=$ $0.005), 1.64(95 \%$ CI $1.08-2.50 ; P=0.020)$, and $2.25(95 \%$ CI $1.33-3.80 ; P=0.003$ ), respectively (Figure 2A-2C). No such association was observed in Caucasians and Asians. The ORs for the Caucasian subgroup were 1.32 (95\% CI $0.90-1.93 ; P=0.160), 1.24$ (95\% CI $0.84-1.82 ; P=0.276)$, and 1.55 (95\% CI $0.86-2.81 ; P=0.145)$, respectively. The ORs for the Asian subgroup were 0.83 (95\% CI $0.51-$ 1.35; $P=0.451), 0.85$ (95\% CI $0.50-1.44 ; P=0.543)$, and 0.55 (95\% CI $0.03-9.48 ; P=0.682)$, respectively (Figure 2A-2C).

Upon subgroup analysis by disease type, we found an association between the G894T polymorphism and premature MI susceptibility when all three genetic
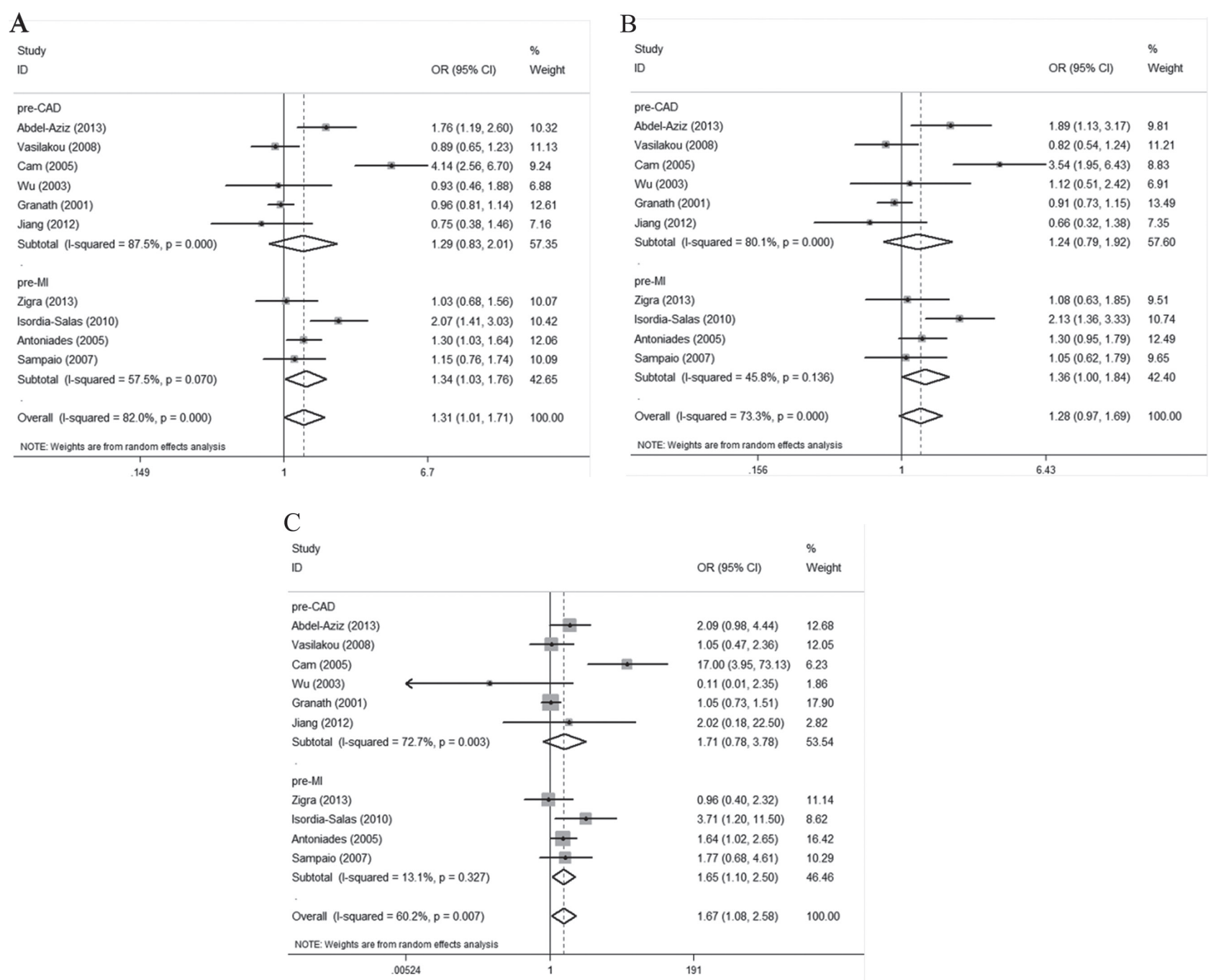

Figure 3: Forest plots of the ORs with $95 \%$ CIs, using different genetic models, for the association between the G894T polymorphism and the risk of CAD in patients stratified by type of disease. (A) Allelic, (B) dominant, and (C) recessive models.

models were employed. The ORs for the premature MI subgroup were $1.34(95 \%$ CI $1.03-1.76 ; P=0.032)$, $1.36(95 \%$ CI $1.00-1.84 ; P=0.047)$, and $1.65(95 \%$ CI $1.10-2.50 ; P=0.017$ ), respectively (Figure $3 \mathrm{~A}-3 \mathrm{C}$ ). No evidence of any association between the polymorphism and premature CAD susceptibility was apparent. The ORs for the premature CAD subgroup were $1.29(95 \%$ CI $0.83-2.01 ; P=0.261), 1.24$ (95\% CI 0.79-1.92; $P=0.349)$, and 1.71 (95\% CI 0.78-3.78; $P=0.181)$, respectively (Figure $3 \mathrm{~A}-3 \mathrm{C}$ ).

\section{Sensitivity analysis}

We assessed the influence of each study on the pooled ORs by omitting the studies one at a time. No study significantly affected the pooled ORs of the allelic, dominant, or recessive models (Figure 4A-4C), confirming the reliability of our results. 


\section{Publication bias}

No significant publication bias was detected by Begg's test (allelic model: $P=0.721$, recessive model: $P=0.466$, allele analysis: $P=0.721$ ) or Egger's regression test (allelic model: $P=0.332$, recessive model: $P=0.326$, allele analysis: $P=0.362$ ). The funnel plots were not asymmetric (Figure 5A-5C).

\section{DISCUSSION}

CAD is a complex disease influenced by both genetic and environmental factors. Apart from the known traditional risk factors (diabetes mellitus, hypertension, hyperlipidemia, obesity, and smoking), genetic factors also play important roles in pathogenesis and disease development $[3,25]$. Those with early-onset CAD constitute a relatively small proportion of all patients with CAD; younger patients account for $5-10 \%$ of all MIs [26-27]. However, exploration of the pathogenesis of premature CAD is important; the prognosis is poor and its impact on individuals, families, and societies

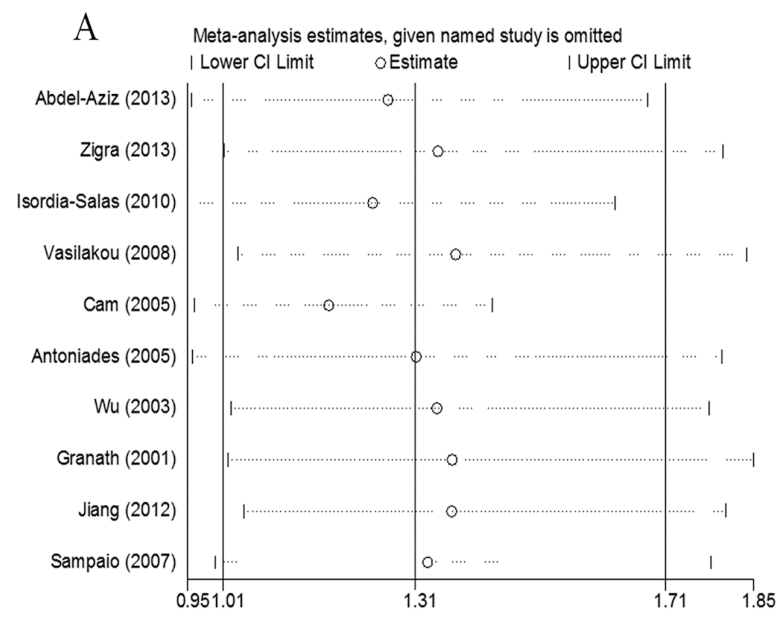

devastating. Compared with mature $\mathrm{CAD}$, premature $\mathrm{CAD}$ is more likely to be influenced by genetic factors $[3,28]$. As mentioned above, eNOS plays an atheroprotective role. Several polymorphisms of the eNOS gene have been reported to be associated with CAD risk, among which G894T and T786C are the most clinically relevant $[21,29]$. G894T polymorphism results in reduced eNOS enzymatic activity and decreased production of NO by endothelial cells [30]. Reduced eNOS activity causes an increase in smooth muscle cell proliferation after vascular injury, and inhibition of the endothelial NO pathway are present in atherosclerosis [31-32]. Zhang et al. reported eNOS G894T polymorphism may play an important role in CAD development among Asia population [33]. However, reports of the association between the eNOS G894T polymorphism and the risk of premature CAD have been inconsistent.

To the best of our knowledge, our present metaanalysis of 10 studies and 3,990 participants is the first to assess the association between the G894T (Glu298Asp) eNOS polymorphism and the risk of premature CAD. Our overall analysis revealed a significant association

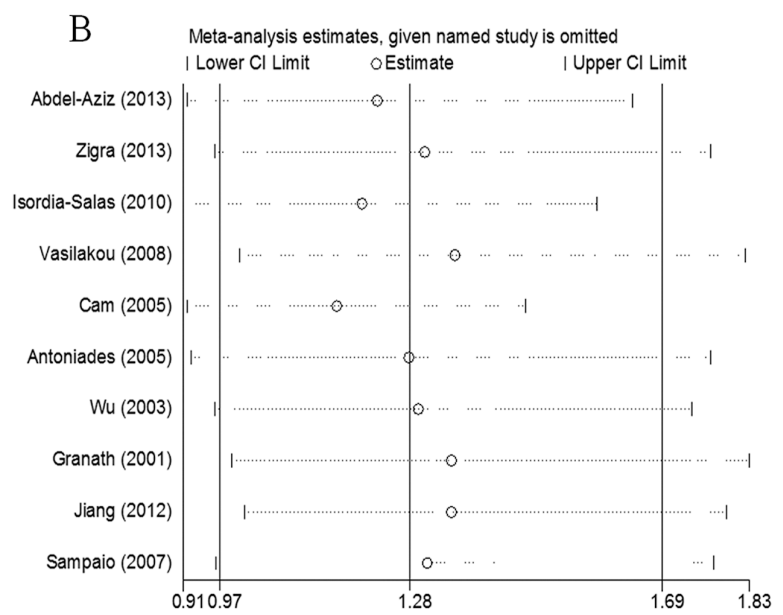

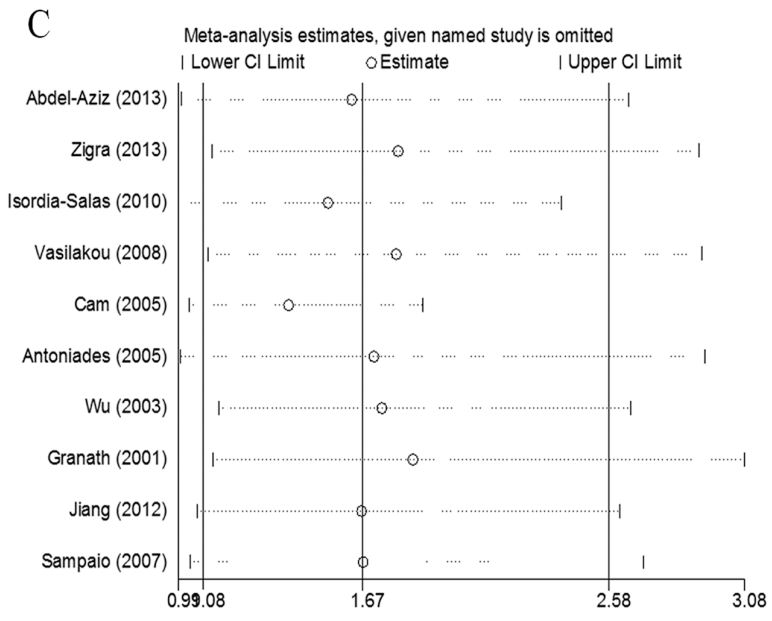

Figure 4: The effect of each study on the overall outcome, as revealed by omitting each study one at a time when various genetic models were evaluated. (A) Allelic, (B) dominant, and (C) recessive models. 
between the polymorphism and the risk of premature CAD in all three genetic models evaluated, indicating that the polymorphism may play an important role in the development of premature CAD.

The influence of genetic polymorphisms can be complicated and may differ among various races and geographical regions. Thus, we performed stratification analyses by patient ethnicity. All models revealed a significant association between the G894T polymorphism and premature CAD in mixed populations, but not in Caucasians and Asians. However, only two of the studies focused on Asian populations in this meta-analysis. Further studies are essential to determine whether the observed geographical variability is attributable to differences in genetic backgrounds. Upon further subgroup analyses according to CAD subtype, the G894T polymorphism was correlated with the development of premature MI, but not premature CAD. A possible explanation is that different genetic variants influence the development of coronary atherosclerosis and $\mathrm{MI}$, consistent with the observations of prior studies [34-35]. In addition, the sample sizes of the included studies and the number of studies evaluated may have been too small to allow detection of all potential associations.

Some limitations of our work should be addressed. First, although we collected all eligible studies, the sample sizes were small, particularly in the subgroup analyses, increasing the risk of false-positives or -negatives. Studies with larger sample sizes are required. Second, progression of premature CAD is multifactorial. Given the limited data, we did not analyze our findings in terms of disease, age, or sex. Certain environmental and lifestyle factors may influence the observed associations. The potential roles played by smoking, hypertension, diabetes mellitus, and obesity must be evaluated. Third, although neither the funnel plot nor Egger's test revealed any publication bias, such bias remains possible.

In conclusion, we found that the G894T polymorphism was associated with a risk of premature CAD, particularly in those experiencing premature MI. Thus, testing for the eNOS G894T polymorphism may be useful for clinical assessment and prediction of premature CAD.
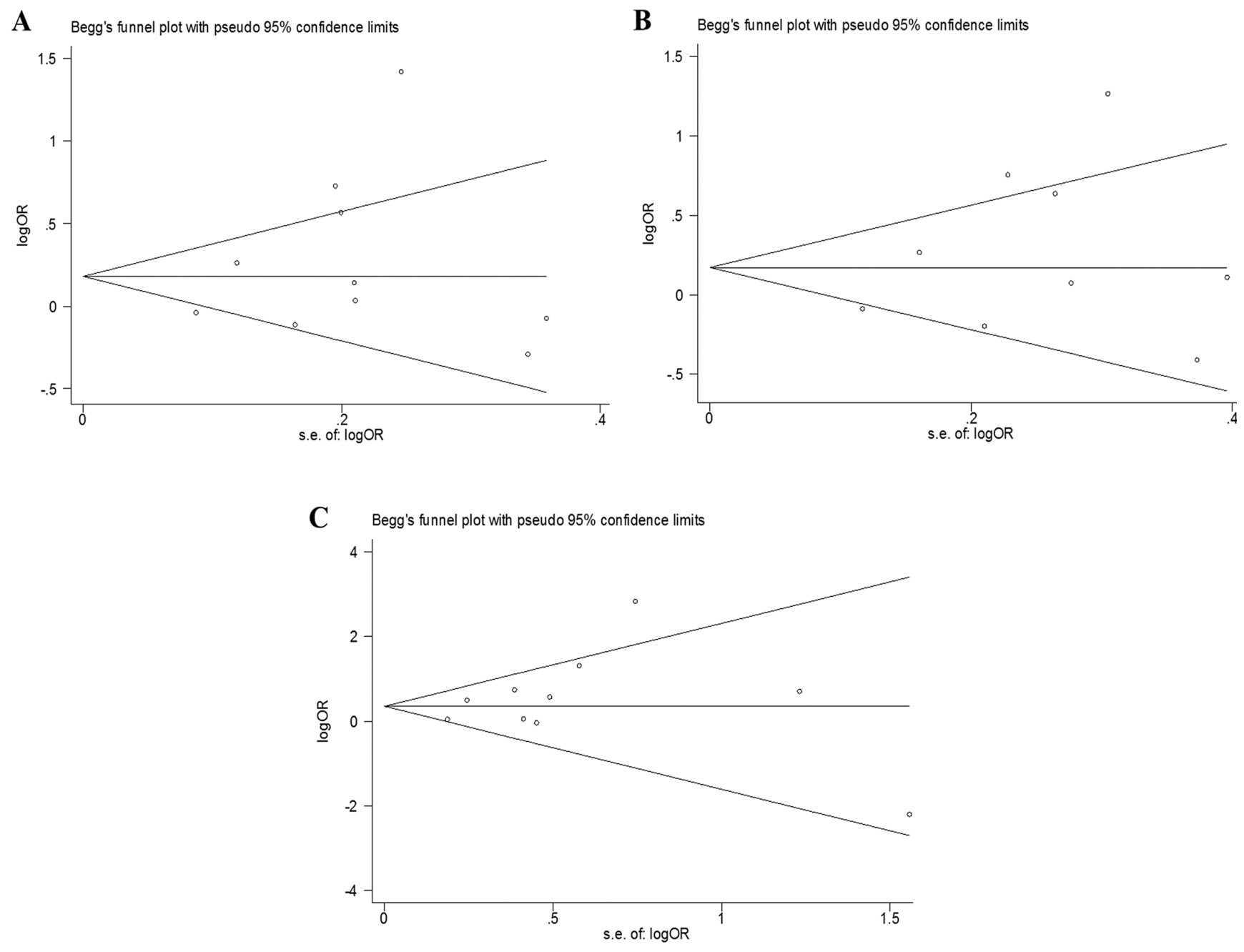

Figure 5: The funnel plots used to assess publication bias. (A) Allelic, (B) dominant, and (C) recessive models. 


\section{MATERIALS AND METHODS}

\section{Search strategy}

Two independent reviewers searched Pubmed, Embase, the Chinese Biomedical Literature Database, and the Cochrane library database (up to December 2016) using the following terms: ('coronary artery disease' OR 'coronary heart disease' OR 'myocardial infarction' OR 'angina') AND ('premature' OR 'young' OR 'early onset') AND ('G894T' OR 'Glu298Asp' OR 'endothelial nitric oxide synthase'). We perused the reference lists of retrieved articles to identify further potentially relevant studies. Any disagreement was resolved by discussion among the team. We retrieved only texts in English and Chinese. If studies contained overlapping data, only the study with the largest group of subjects, or the most recent study, was included.

\section{Inclusion and exclusion criteria}

The inclusion criteria were studies (1) that assessed the association between the G894T (Glu298Asp) polymorphism and the risk of premature CAD/MI, (2) that were either a case-control or a cohort study, (3) in which all patients had been diagnosed with premature CAD/MI, and the healthy controls did not have CAD, (4) in which the CAD diagnosis was based on coronary angiography and the MI diagnosis on electrocardiography and clinical and laboratory data, and (4) in which the genotype distributions of the controls were in Hardy-Weinberg equilibrium (HWE).

We excluded reviews, case reports, letters, editorials, conference abstracts, and duplicate publications of data from the same study.

\section{Data extraction}

Data were extracted independently by two authors; any disagreement was resolved by discussion among the review team. We extracted the name of the first author, publication year, patient ethnicity, study design, definition of the cases, source of the controls, mean age, age range, male percentage, numbers of cases and controls, genotype distributions of the cases and controls, and the genotyping method used. Authors were contacted with requests for original data when such data were absent from the reports.

\section{Quality assessment}

The quality of eligible studies was assessed by using the Newcastle-Ottawa scale (NOS). NOS quality scores ranged between 0 and 9 stars. Studies with a score $\geq 7$ were considered high quality, while studies with a score $\leq 5$ were deemed low quality.

\section{Statistical snalysis}

The association between the eNOS G894T polymorphism and the risk of premature CAD was assessed by calculating odds ratios (ORs) with 95\% confidence intervals (CIs). We performed an overall comparison as well as a stratification analysis based on patient ethnicity. Each OR and 95\% CI were calculated by reference to an allelic model ( $\mathrm{T}$ vs. G), a dominant model ([GT + TT ] vs. GG), and a recessive model (TT vs. $[\mathrm{GG}+\mathrm{GT}])$. The chi-squared test was used to determine whether the control genotype distributions were in HWE. Heterogeneity among studies was evaluated by calculation of $Q$ test and $\mathrm{I}^{2}$ statistics. A $P$ value $<0.05$ or an $I^{2}$ value $>50 \%$ indicated that heterogeneity was in play among studies; the random-effects Mantel-Haenszel model was used to compare the data of such studies. Otherwise, the fixed-effects Mantel-Haenszel model was employed. Subgroup analysis was performed by ethnicity and CAD subtype. Publication bias was assessed by drawing a funnel plot and using Egger's test. During the sensitivity analysis, we omitted individual studies to evaluate the reliability of our results. All data were analyzed using STATA 12.0 software for Windows. A $P$ value $<0.05$ was considered to reflect statistical significance.

\section{Abbreviations}

CAD: coronary artery disease; eNOS: endothelial nitric oxide synthase; NO: nitric oxide; MI : myocardial infarction; HWE : Hardy-Weinberg equilibrium.

\section{ACKNOWLEDGMENTS}

This study was supported by grants to ChengChun Tang from the Natural Science Foundation of China (Research Grant \#81370225) and Natural Science Foundation of China (Research Grant \#81670237).

\section{CONFLICTS OF INTEREST}

The authors declare no conflicts of interest.

\section{REFERENCES}

1. Lloyd-Jones D, Adams RJ, Brown TM, Carnethon M, Dai S, De Simone G, Ferguson TB, Ford E, Furie K, Gillespie C, Go A, Greenlund K, Haase N, et al. Heart disease and stroke statistics--2010 update: a report from the American Heart Association. Circulation. 2010; 121:e46-e215.

2. Smith SC Jr, Greenland P, Grundy SM. AHA Conference Proceedings. Prevention conference V: Beyond secondary prevention: Identifying the high-risk patient for primary prevention: executive summary. American Heart Association. Circulation. 2000; 101:111-116. 
3. Mohammad AM, Jehangeer HI, Shaikhow SK. Prevalence and risk factors of premature coronary artery disease in patients undergoing coronary angiography in Kurdistan, Iraq. BMC Cardiovasc Disord. 2015; 15:155.

4. Cam SF, Sekuri C, Tengiz I, Ercan E, Sagcan A, Akin M, Berdeli A. The G894T polymorphism on endothelial nitric oxide synthase gene is associated with premature coronary artery disease in a Turkish population. Thromb Res. 2005; 116:287-292.

5. Panagiotakos DB, Rallidis LS, Pitsavos C, Stefanadis C, Kremastinos D. Cigarette smoking and myocardial infarction in young men and women: a case-control study. Int J Cardiol. 2007; 116:371-375.

6. Rallidis LS, Gialeraki A, Merkouri E, Liakos G, Dagres N, Sionis D, Travlou A, Lekakis J, Kremastinos DT. Reduced carriership of $4 \mathrm{G}$ allele of plasminogen activator inhibitor-1 4G/5G polymorphism in very young survivors of myocardial infarction. J Thromb Thrombolysis. 2010; 29:497-502.

7. De Caterina R. Endothelial dysfunctions: common denominators in vascular disease. Curr Opin Clin Nutr Metab Care. 2000; 3:453-467.

8. Gimbrone MA Jr. Vascular endothelium, hemodynamic forces, and atherogenesis. Am J Pathol. 1999; 155:1-5.

9. Moncada S. The L-arginine: nitric oxide pathway, cellular transduction and immunological roles. Adv Second Messenger Phosphoprotein Res. 1993; 28:97-99.

10. Hingorani AD. Polymorphisms in endothelial nitric oxide synthase and atherogenesis: John French Lecture 2000. Atherosclerosis. 2001; 154:521-527.

11. Marsden PA, Heng HH, Scherer SW, Stewart RJ, Hall AV, Shi XM, Tsui LC, Schappert KT. Structure and chromosomal localization of the human constitutive endothelial nitric oxide synthase gene. J Biol Chem. 1993; 268:17478-17488.

12. Hingorani AD, Liang CF, Fatibene J, Lyon A, Monteith S, Parsons A, Haydock S, Hopper RV, Stephens NG, O'Shaughnessy KM, Brown MJ. A common variant of the endothelial nitric oxide synthase (Glu298- $\rightarrow$ Asp) is a major risk factor for coronary artery disease in the UK. Circulation. 1999; 100:1515-1520.

13. Rossi GP, Cesari M, Zanchetta M, Colonna S, Maiolino G, Pedon L, Cavallin M, Maiolino P, Pessina AC. The T-786C endothelial nitric oxide synthase genotype is a novel risk factor for coronary artery disease in Caucasian patients of the GENICA study. J Am Coll Cardiol. 2003; 41:930-937.

14. Cine N, Hatemi AC, Erginel-Unaltuna N. Association of a polymorphism of the ecNOS gene with myocardial infarction in a subgroup of Turkish MI patients. Clin Genet. 2002; 61:66-70.

15. Yoshimura M, Yasue H, Nakayama M, Shimasaki Y, Sumida H, Sugiyama S, Kugiyama K, Ogawa H, Ogawa Y, Saito Y, Miyamoto Y, Nakao K. A missense Glu298Asp variant in the endothelial nitric oxide synthase gene is associated with coronary spasm in the Japanese. Hum Genet. 1998; 103:65-69.

16. Wu YW, Lee CM, Hsu SM, Lee YT. Association between endothelial nitric oxide synthase polymorphisms and the risk of premature coronary artery disease in Taiwan. Journal of Internal Medicine of Taiwan. 2003; 14:1-10.

17. Isordia-Salas I, Leanos-Miranda A, Borrayo-Sanchez G. The Glu298ASP polymorphism of the endothelial nitric oxide synthase gene is associated with premature ST elevation myocardial infarction in Mexican population. Clin Chim Acta. 2010; 411:553-557.

18. Granath B, Taylor RR, van Bockxmeer FM, Mamotte CD. Lack of evidence for association between endothelial nitric oxide synthase gene polymorphisms and coronary artery disease in the Australian Caucasian population. J Cardiovasc Risk. 2001; 8:235-241.

19. Vasilakou M, Votteas V, Kasparian C, Pantazopoulos N, Dedoussis G, Deltas C, Nastos P, Nikolakis D, Lamnissou K. Lack of association between endothelial nitric oxide synthase gene polymorphisms and risk of premature coronary artery disease in the Greek population. Acta Cardiol. 2008; 63:609-614.

20. Antoniades C, Tousoulis D, Vasiliadou C, Pitsavos C, Chrysochoou C, Panagiotakos D, Tentolouris C, Marinou K, Koumallos N, Stefanadis C. Genetic polymorphism on endothelial nitric oxide synthase affects endothelial activation and inflammatory response during the acute phase of myocardial infarction. J Am Coll Cardiol. 2005; 46:1101-1109.

21. Zigra AM, Rallidis LS, Anastasiou G, Merkouri E, Gialeraki A. eNOS gene variants and the risk of premature myocardial infarction. Dis Markers. 2013; 34:431-436.

22. Abdel-Aziz TA, Mohamed RH. Association of endothelial nitric oxide synthase gene polymorphisms with classical risk factors in development of premature coronary artery disease. Mol Biol Rep. 2013; 40:3065-3071.

23. Jiang JG, Liu J, Chen JG. Correlation Study on Polymorphisms of the Endodermis Nitricoxide Synthase Gene and N5, N10 Methylene Tetrahydrofolate Reductase Gene in Han Patients with Premature Coronary Artery Disease in the Suwan Region. Chinese Journal of Arteriosclerosis. 2012; 20:463-468.

24. Sampaio MF, Hirata MH, Hirata RD, Santos FC, Picciotti R, Luchessi AD, de Quateli Doi S, Armaganijan D, Batlouni $\mathrm{M}$. AMI is associated with polymorphisms in the NOS3 and FGB but not in PAI-1 genes in young adults. Clin Chim Acta. 2007; 377:154-162.

25. Gluba A, Banach M, Mikhailidis DP, Rysz J. Genetic determinants of cardiovascular disease: the reninangiotensin-aldosterone system, paraoxonases, endothelin-1, nitric oxide synthase and adrenergic receptors. In Vivo. 2009; 23:797-812.

26. Isordia-Salas I, Mendoza-Valdez AL, Almeida-Gutierrez E, Borrayo-Sanchez G. Genetic factors of the hemostatic 
system in young patients with myocardial infarction. Cir Cir. 2010; 78:93-97.

27. O'Gara PT, Kushner FG, Ascheim DD, Casey DE Jr, Chung MK, de Lemos JA, Ettinger SM, Fang JC, Fesmire FM, Franklin BA, Granger CB, Krumholz HM, Linderbaum JA, et al. 2013 ACCF/AHA guideline for the management of ST-elevation myocardial infarction: executive summary: a report of the American College of Cardiology Foundation/ American Heart Association Task Force on Practice Guidelines: developed in collaboration with the American College of Emergency Physicians and Society for Cardiovascular Angiography and Interventions. Catheter Cardiovasc Interv. 2013; 82:E1-27.

28. Roncaglioni MC, Santoro L, D’Avanzo B, Negri E, Nobili A, Ledda A, Pietropaolo F, Franzosi MG, La Vecchia C, Feruglio GA. Role of family history in patients with myocardial infarction. An Italian case-control study. GISSI-EFRIM Investigators. Circulation. 1992; 85:2065-2072.

29. Liu D, Jiang Z, Dai L, Zhang X, Yan C, Han Y. Association between the $-786 \mathrm{~T}>\mathrm{C}$ 1polymorphism in the promoter region of endothelial nitric oxide synthase (eNOS) and risk of coronary artery disease: a systematic review and metaanalysis. Gene. 2014; 545:175-183.

30. Hirata RD, Salaza LA, Cavalli SA, Yoshioka KK, Matsumoto LO, Santos ST, Giannini SD, Forti N, Diament J, Doi SQ, Hirata MH. A method to detect the G894T polymorphism of the NOS3 gene. Clinical validation in familial hypercholesterolemia. Clin Chem Lab Med. 2002; 40:436-440.

31. McCullagh KJ, Cooney R, O'Brien T. Endothelial nitric oxide synthase induces heat shock protein HSPA6 (HSP70B') in human arterial smooth muscle cells. Nitric Oxide. 2016; 52:41-48.

32. Kerkeni M, Addad F, Chauffert M, Myara A, Ben Farhat M, Miled A, Maaroufi K, Trivin F. Hyperhomocysteinemia, endothelial nitric oxide synthase polymorphism, and risk of coronary artery disease. Clin Chem. 2006; 52:53-58.

33. Zhang K, Bai P, Shi S, Zhou B, Wang Y, Song Y, Rao L, Zhang L. The G894T polymorphism on endothelial nitric oxide synthase gene is associated with increased coronary heart disease among Asia population: evidence from a Meta analysis. Thromb Res. 2012; 130:192-197.

34. Reilly MP, Li M, He J, Ferguson JF, Stylianou IM, Mehta NN, Burnett MS, Devaney JM, Knouff CW, Thompson JR, Horne BD, Stewart AF, Assimes TL, et al. Identification of ADAMTS7 as a novel locus for coronary atherosclerosis and association of $\mathrm{ABO}$ with myocardial infarction in the presence of coronary atherosclerosis: two genome-wide association studies. Lancet. 2011; 377:383-392.

35. Horne BD, Carlquist JF, Muhlestein JB, Bair TL, Anderson JL. Association of variation in the chromosome 9p21 locus with myocardial infarction versus chronic coronary artery disease. Circ Cardiovasc Genet. 2008; 1:85-92. 